\title{
Remote sensing of volcanic ash plumes from thermal infrared: a case study analysis from SEVIRI, MODIS and IASI instruments
}

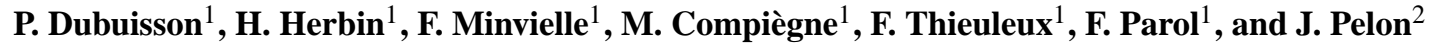 \\ ${ }^{1}$ LOA, UMR8518, CNRS, Université Lille 1, Villeneuve d'Ascq, France \\ ${ }^{2}$ LATMOS, UMR8190, CNRS, Université Pierre et Marie Curie, Paris, France
}

Correspondence to: P. Dubuisson (philippe.dubuisson@univ-lille1.fr)

Received: 14 February 2013 - Published in Atmos. Meas. Tech. Discuss.: 20 March 2013

Revised: 11 December 2013 - Accepted: 20 December 2013 - Published: 3 February 2014

\begin{abstract}
The Eyjafjallajökull eruption, which occurred during May 2010, is used as a case study to evaluate the consistency of the detection and characterization of volcanic ash plumes from different thermal infrared instruments. In this study, the well-known split window technique is used to retrieve the optical thickness and the effective particle size, and to estimate the mass concentration of volcanic particles from brightness temperatures measured in the infrared atmospheric window $(8-12 \mu \mathrm{m})$. Retrievals are obtained for several mineral compositions whose optical properties are computed using Mie theory accounting for spectral variations of the refractive index. The impacts of errors in atmospheric parameters on the a posteriori uncertainties have been analysed. This analysis confirmed that major sources of errors are the layer altitude, the particle composition and, most of all, the size distribution for which uncertainties in retrievals can reach $50 \%$ in mass loading estimates. This retrieval algorithm is then applied to measurements acquired near-simultaneously from MODIS, SEVIRI and IASI spaceborne instruments, using two channels around $11 \mu \mathrm{m}$ and $12 \mu \mathrm{m}$. The retrievals are in close agreement when taking into account the different spatial and spectral configurations, and deviations between retrievals remain less than the uncertainties due to errors in atmospheric parameters. This analysis demonstrates the robustness of the retrieval method and the consistency of observations from these instruments for volcanic ash plume monitoring.
\end{abstract}

\section{Introduction}

Volcanoes are important sources of aerosol particles and gas phase precursors of secondary air pollutants that can have significant effects on solar and infrared atmospheric radiation, with consequences for atmospheric radiative forcing and climate (Le Treut et al., 2007). In addition, large plumes of ash emitted into the atmosphere can have impacts on aviation security and air traffic (Prata and Tupper, 2009; International Civil Aviation Organization (ICAO), 2001; Alexander, 2013). In this context, satellite instruments provide efficient tools for spatio-temporal monitoring of ash plumes. Together, with in situ measurements and numerical simulations, this allows mitigation of aviation hazards. For instance, the explosive eruption of the Eyjafjallajökull volcano in Iceland during April-May 2010 has shown the importance of combining measurements and models to derive physical characteristics of volcanic aerosols and to study the plume spatial structure and dispersion (Zehner, 2010; Millington et al., 2012; Webley et al., 2012).

Many methodologies have been proposed for plume observations and characterization from active remote sensing technology or using passive sensors from space (for a complete list, see for instance Thomas and Watson, 2010; Zehner, 2010). From the latter, the analysis of spectral information gives access to optical and physical properties of volcanic ash plumes from which parameters relevant to flight safety can be derived (e.g. the mass concentration of particles). The split window technique has been used extensively to characterize atmospheric particles using channels in the infrared atmospheric window $(8-13 \mu \mathrm{m})$ centred approximately at $11 \mu \mathrm{m}$ and $12 \mu \mathrm{m}$. It is based on the spectral variation of the 
extinction efficiency of ash particles in the infrared spectral range. This method is currently employed for remote sensing of semitransparent clouds (Inoue, 1985, 1987; Parol et al., 1991; Dubuisson et al., 2008; Cooper and Garett, 2010), and is also used intensively for characterization of volcanic particles (Prata, 1989a, b; Wen and Rose, 1994; Schneider et al., 1995). This approach has been applied to polar satellite sensors such as the Advanced Very High Resolution Radiometer (AVHRR) or the Along Track Scanning Radiometer (ATSR) (Prata, 1989a; Wen and Rose, 1994; Prata and Grant, 2001), the Moderate Resolution Imaging Spectroradiometer (MODIS) (Hillger and Clark, 2002; Watson et al., 2004; Tupper at al., 2004; Corradini et al., 2011), as well as to sensors on-board geostationary platforms such as the Geostationary Operational Environmental Satellite (GOES) (Yu et al., 2002) or the Spin Enhanced Visible and Infrared Imager (SEVIRI) data (Prata and Kerkmann, 2007; Corradini et al., 2008; Francis et al., 2012; Prata and Prata, 2012). The capabilities and limitations of the split window technique have been discussed in Wen and Rose (1994), Prata et al. (2001) and Pavolonis et al. (2006).

In this paper, an analysis of the results obtained by applying the same retrieval algorithm to a volcanic plume is presented using observations from MODIS, SEVIRI and IASI space-borne instruments. We focus this study on the eruption of the Eyjafjallajökull volcano on 6 May 2010 because it was observed near-simultaneously by these space infrared sensors. The retrieval method is based on the split window technique and accurate radiative transfer calculations (Dubuisson et al., 2005, 2008). The goal of this study is not to present a new operational algorithm, but to study the consistency of retrievals using the same algorithm from different infrared instruments and to analyse the uncertainties and limitations of these retrievals. As far as we know, there is no previous similar inter-comparison.

This paper is organized as follows: MODIS, SEVIRI and IASI instruments are briefly described in Sect. 2. The retrieval algorithm is presented in Sect. 3. Retrievals of optical thickness, particle effective radius, and mass loading estimation of the plume from two infrared channels are presented and analysed in Sect. 4, using SEVIRI observations. In Sect. 5, the retrieval algorithm is applied in the same way for the three considered infrared sensors to assess the consistency of measurements; spatial distributions as well as mean values of retrieved parameters are compared. The retrieval algorithm sensitivity to errors in atmospheric parameters, such as the particle type, plume altitude or particle size distribution, is also presented. Finally, the inter-comparison results are discussed in terms of the a posteriori retrieved parameter uncertainties.

\section{Description of the instruments}

Many space-borne broadband sensors (such as MODIS, SEVIRI, IIR or AVHRR) with spectral channels in the infrared window are available to monitor volcanic plumes. These sensors are generally designed to collect aerosol properties on a global scale. More recently, hyperspectral sensors such as IASI (Schlüssel et al., 2005; Clerbaux et al., 2009) or GOSAT (Kuze et al., 2009), which are dedicated to gas species measurements, have been used to provide useful aerosol information (Clarisse et al., 2010a; Herbin et al., 2013). In our study, three instruments have been considered:

- SEVIRI on-board the geostationary Meteosat Second Generation (MSG) satellite (Schmetz et al., 2002). Among the available channels, three are centred in the infrared window at 8.7, 10.8 and $12 \mu \mathrm{m}$. Data are collected every $15 \mathrm{~min}$ for the whole 70 degree disk, with a spatial resolution ranging from $3 \times 3 \mathrm{~km}^{2}$ at the subsatellite to about $10 \times 10 \mathrm{~km}^{2}$ near the edges of the scan. Note that the area study considered in this paper is near the limit of coverage for SEVIRI. However, Prata and Prata (2012) emphasise the advantage of viewing a volcanic plume from an acute angle using SEVIRI data, in particular in the case of high latitudes. Indeed, even in the case of small ash concentrations, retrievals are possible because of the longer optical path in the ash cloud, leading to larger brightness temperature differences.

- MODIS (Moderate Resolution Imaging Spectroradiometer) on-board the two polar orbiting satellites AQUA and TERRA. This instrument acquires data in 36 channels with three channels in the infrared window $(8.6,11$ and $12 \mu \mathrm{m})$ at $1 \times 1 \mathrm{~km}^{2}$ spatial resolution, with a viewing swath width of $2330 \mathrm{~km}$ and is designed to retrieve aerosol properties (Remer et al., 2005).

- IASI (Infrared Atmospheric Sounding Interferometer). IASI is a payload element of the polar-orbiting MetOp satellites using a Fourier Transform Spectrometer operating in the $3.7-15.5 \mu \mathrm{m}$ spectral range, with an apodized spectral resolution of $0.5 \mathrm{~cm}^{-1}$ and, consequently, includes the infrared window. This instrument analyses an atmospheric cell of about $50 \times 50 \mathrm{~km}^{2}$ and the effective field of view (EFOV) consists of a $2 \times 2$ matrix of so-called instantaneous fields of view (IFOV), with a circular IFOV of $3.33^{\circ}$ which corresponds to a ground resolution of $12 \mathrm{~km}$ at nadir (Clerbaux et al., 2009).

In this study, satellite data have been processed and made available by the ICARE Data and Services Centre (MODIS and SEVIRI) and by the Ether data centre (IASI). Comparisons are also possible with the three-channel Imaging Infrared Radiometer (IIR) on-board CALIPSO (Garnier et al., 
2012; Sourdeval et al., 2012). Indeed, IIR performs nearsimultaneous measurements with MODIS/Aqua with the same spatial resolution. However, because the IIR instrument has a very narrow measurement swath, spatio-temporal collocations between IIR observations and volcanic plume are not frequent. Consequently, only a very few pixels are available for comparisons and the IIR instrument has not been considered in this study.

\section{Retrieval methodology}

As mentioned in the introduction, the use of two channels in the thermal infrared allows us to characterize volcanic plumes as well as discriminate cloud contamination and has been applied extensively to satellite measurements. Figure 1 shows the brightness temperature differences (BTD) observed for the Eyjafjallajökull eruption on 6 May 2010, using MODIS infrared channels at $11 \mu \mathrm{m}$ and $12 \mu \mathrm{m}$, and illustrates the different spectral behaviour from cloud and volcanic particles. A plume characterization is then available using BTDs from the split window technique. A simple algorithm has then been developed to retrieve optical and physical properties of volcanic plumes using BTDs from infrared satellite measurements. This algorithm is based on accurate radiative transfer calculations using realistic spectral variations of the refractive indices, for several volcanic particle types. As specified previously, the aim of this study is not to present a new operational retrieval algorithm, but to analyse the observations' consistency from different infrared instruments (MODIS, SEVIRI and IASI) using the same retrieval algorithm. The radiative transfer modelling and the retrieval methods used are described briefly hereafter.

\subsection{Radiative transfer modelling}

Brightness temperatures (BT) are simulated using the FASDOM radiative transfer code (Dubuisson et al., 2005). This code was originally developed for the IIR/CALIPSO (Garnier et al., 2012) radiometer and has been adapted to MODIS and SEVIRI sensors (Doutriaux-Boucher and Dubuisson, 2009; Borde et al., 2010). Infrared radiances are calculated by solving the radiative transfer equation for a vertically inhomogeneous plane-parallel atmosphere using the DISORT radiative transfer code developed by Stamnes et al. (1988). Gaseous line absorption (mainly $\mathrm{H}_{2} \mathrm{O}, \mathrm{CO}_{2}, \mathrm{O}_{3}, \mathrm{CH}_{4}$ and $\mathrm{N}_{2} \mathrm{O}$ ) and absorption continua for $\mathrm{H}_{2} \mathrm{O}$ and $\mathrm{CO}_{2}$ are considered on the basis of the correlated $k$ distribution method (Lacis and Oinas, 1991; Kratz, 1995). This approach allows us to account for interactions between gaseous absorption and multiple scattering processes in the presence of cloud and/or aerosol layers, considered as plane parallel and homogeneous media. Conversion tables of brightness temperature to radiance, as well as gaseous absorption, have been calculated using the spectral response functions of the sensors.

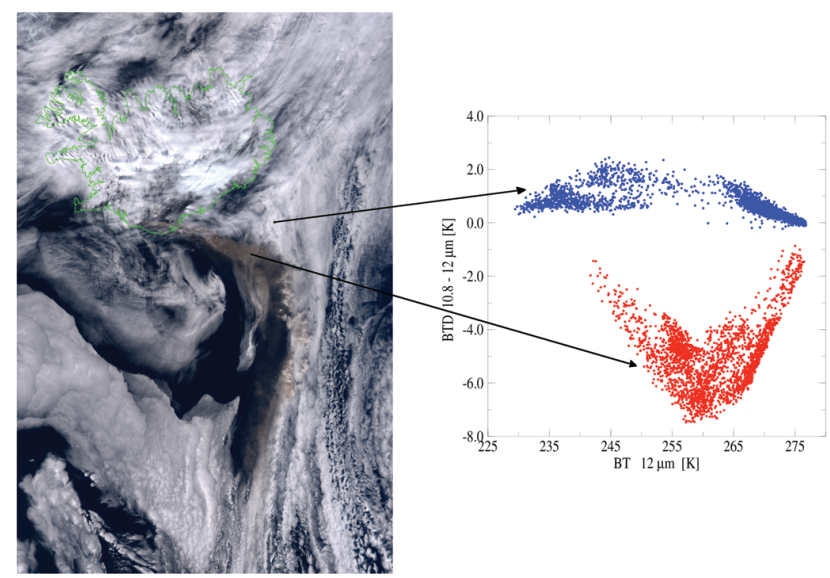

Fig. 1. Example of brightness temperature differences (BTD) observed for the Eyjafjallajökull volcanic plume using MODIS/Terra data. The RGB composite image is presented on 6 May 2010 (left) at 11:55 UTC. BTD $(11-12 \mu \mathrm{m})$ are reported as a function of brightness temperature (BT) at $12 \mu \mathrm{m}$ (right), in the volcanic plume (red) or a cloudy area (blue).

Note that in the case of IASI, radiative transfer calculations have been performed with the same code, but following two different approaches: (1) by selecting three channels without gaseous line absorption around 8.7, 11 and $12 \mu \mathrm{m}$ or (2) by integrating the IASI spectrum over the SEVIRI and MODIS spectral responses. Figure 2 presents a brightness temperature spectrum from IASI measured on 6 May 2010, in the volcanic plume presented in Fig. 1. This IASI spectrum illustrates the so-called "V-shape" feature of the BT in the $800-1200 \mathrm{~cm}^{-1}$ spectral range. The spectral position of IASI monochromatic channels used in this study is reported in Fig. 2, as well as brightness temperatures obtained after integrating the IASI spectrum over MODIS spectral responses. Figure 2 shows close BT using these two approaches. Although it is easier to simulate brightness temperature from a single IASI channel without gaseous absorption line, integrating brightness temperatures over MODIS or SEVIRI channels has been also considered in this study to perform comparisons in similar conditions.

FASDOM requires the atmospheric profile (pressure, temperature and absorbers) as well as single scattering properties of particles as a priori parameters. Optical properties of liquid clouds and aerosols are calculated from the Mie theory assuming spherical particles. This assumption is reasonable in the thermal infrared spectrum (Mehta et al., 2009) in contrast to the solar spectrum for which the particle shape has a non-negligible influence on the top of atmosphere radiances. Several models (i.e. spectral refractive index and size distribution) are considered for volcanic particles and summarized in Table 1. From these data, single scattering properties of particles (extinction coefficient, single scattering albedo and asymmetry factor) are computed assuming a monomodal lognormal formulation for the particle size distribution: 
Table 1. Density $D$ at $293 \mathrm{~K}$ of particle types and refractive indices references used in this study.

\begin{tabular}{lrl}
\hline Particle type & $D\left(\mathrm{~g} \mathrm{~cm}^{-3}\right)$ & Ref. \\
\hline Andesite & 2.65 & Pollack et al. (1973) \\
Volcanic Ash & 2.8 & Shettle and Fenn (1979) \\
Basalt & 2.9 & Pollack et al. (1973) \\
Hematite & 5.1 & Longtin et al. (1988) \\
Obsidian & 2.65 & Pollack et al. (1973) \\
Quartz & 2.65 & Longtin et al. (1988) \\
\hline
\end{tabular}

$n(r)=\frac{N_{0}}{r \ln \sigma \sqrt{2 \pi}} \exp \left(-\frac{1}{2} \frac{\left[\ln r-\ln r_{0}\right]^{2}}{[\ln \sigma]^{2}}\right)$,

where $N_{0}$ is the total number density, $r$ is the particle radius $(\mu \mathrm{m}), r_{0}$ is the geometric mean radius $(\mu \mathrm{m})$ and $\sigma$ is the geometric standard deviation of the particle size distribution. Note that the standard deviation $\sigma=2$ is used by default in this study, because this value is within the range of particles typically measured (Hess et al., 1998; Dubovik et al., 2002). From this formulation, the effective radius $r_{\mathrm{e}}(\mu \mathrm{m})$ can be defined as:

$r_{\mathrm{e}}=\frac{\int_{0}^{\infty} r^{3} n(r) \mathrm{d} r}{\int_{0}^{\infty} r^{2} n(r) \mathrm{d} r}=r_{0} \sqrt{\ln \sigma}$.

The ash optical thickness is then defined from the extinction efficiency $Q_{\text {ext }}(\lambda, r)$ as:

$\tau_{\mathrm{a}}(\lambda)=\pi L \int_{0}^{\infty} r^{2} Q_{\text {ext }}(\lambda, r) n(r) \mathrm{d} r$,

where $L$ is the thickness of the ash layer.

The split window technique is based on the spectral variation of the particle extinction that can be measured by comparing two thermal infrared channels. To get good accuracy, the single scattering optical properties have been calculated at a high spectral resolution $\left(1 \mathrm{~cm}^{-1}\right)$ and then convoluted with the spectral response of each channel. Practically, lookup tables (LUTs) of these integrated properties have been built for each spectral channel and for each particle type, with geometric mean radius varying from 0.25 to $20 \mu \mathrm{m}$ with a grid step of $0.25 \mu \mathrm{m}$.

\subsection{Retrieval algorithm description}

The retrieval algorithm has been developed following the scheme proposed by Dubuisson et al. (2008). This algorithm was originally developed for cirrus clouds and has been adapted to retrieve properties of volcanic plumes. It can be described in three main stages:

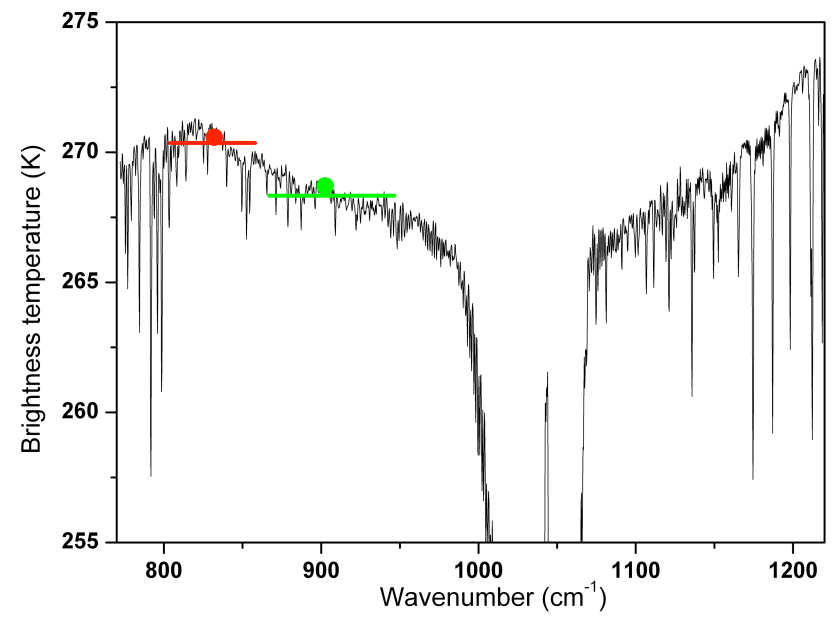

Fig. 2. IASI brightness temperature spectrum measured on 6 May 2010 , in the volcanic plume during the eruption of Eyjafjallajökull (black solid line). Spectral position of IASI channels at $902.50 \mathrm{~cm}^{-1}(11 \mu \mathrm{m}-$ green colour $)$ and $832.00 \mathrm{~cm}^{-1}(12 \mu \mathrm{m} \mathrm{-}$ red colour) used in this study to retrieve plume properties are reported on the spectrum (big dots). This compares with mean brightness temperatures obtained after integrating the IASI spectrum over MODIS spectral responses (horizontal bars). The width of horizontal bars represents the spectral width of MODIS channels.

- As illustrated in Fig. 1, a pixel can be classified as volcanic aerosol using a detection threshold, based on the brightness temperatures for the three channels at $8.7 \mu \mathrm{m}, 11 \mu \mathrm{m}$ and $12 \mu \mathrm{m}$ (see Francis et al., 2012). In this study, ash detection flags have been defined for each instrument from comparisons with the RGB images for the plume on 6 May. As an example, for MODIS data, a pixel is identified as volcanic ash if $\left(\mathrm{BT}_{11 \mu \mathrm{m}}-\mathrm{BT}_{12 \mu \mathrm{m}}<-0.4 \mathrm{~K}\right)$ and if $\left(\mathrm{BT}_{8.7 \mu \mathrm{m}}-\right.$ $\mathrm{BT}_{12 \mu \mathrm{m}}>-4 \mathrm{~K}$ and $\left.\mathrm{BT}_{11 \mu \mathrm{m}}-\mathrm{BT}_{12 \mu \mathrm{m}}<-1 \mathrm{~K}\right)$. These ash detection flags depend on the spectral characteristics and on viewing geometries of sensors and should be better defined for operational applications. This threshold allows us to discriminate efficiently volcanic plumes from clouds; however, some pixels in the plumes with large particle radius or composed of a mixture of aerosol and cloud particles can be rejected.

- A set of brightness temperatures is pre-calculated with the FASDOM code, for channels at $11 \mu \mathrm{m}$ and $12 \mu \mathrm{m}$, to cover a realistic range of effective particle radius $r_{\mathrm{e}}$ from 0.5 to $20 \mu \mathrm{m}$ and aerosol optical thickness $\tau_{\mathrm{a}}$ at $12 \mu \mathrm{m}$ from 0 to 10 . This set is calculated using the LUTs of single scattering properties presented in the previous section and the atmospheric profile obtained from the RAMS model (see below for details) for the considered pixel. In addition, the altitude and the temperature of the ash cloud can be estimated from the RAMS model or CALIOP data, when available. 
- From a pair of brightness temperatures at $11 \mu \mathrm{m}$ and $12 \mu \mathrm{m}$ (i.e. a couple of BTD, BT at $12 \mu \mathrm{m}$ ), observed by a sensor for the considered pixel, retrievals $\left(\tau_{\mathrm{a}}, r_{\mathrm{e}}\right)$ are obtained through linear interpolations from the previous set of pre-calculated brightness temperatures. For a given pixel, a solution is sought separately for every particle type presented in Table 1.

Finally, for each selected pixel, the retrieved parameters are the ash optical thickness at $12 \mu \mathrm{m}, \tau_{\mathrm{a}}$, and the effective radius of particles, $r_{\mathrm{e}}$. In addition, mass loading, $M\left(\mathrm{~g} \mathrm{~m}^{-2}\right)$, which is an important parameter for aviation security, can be easily evaluated from the retrieved effective size and optical thickness as:

$M=\frac{4}{3} \pi \rho r_{\mathrm{e}}^{3} \frac{\tau_{12 \mathrm{mc}}}{k_{\mathrm{e}} L}$,

with $\rho\left(\mathrm{kg} \mathrm{m}^{-3}\right)$ the density of ash particles and $k_{\mathrm{e}}(\mathrm{m})$ the extinction coefficient. Note that the presence of thin clouds can have an important impact on retrievals and must be considered in operational algorithms (Prata and Prata, 2012). However, clouds have not been considered in this study because available measurements from CALIOP have not shown cirrus above the ash layer on 6 May, and most cloudy pixels have been rejected from the detection flag defined above.

Furthermore, we use results from simulations using the RAMS (Regional Atmospheric Modeling System, Pielke et al., 1992; Cotton et al., 2003) 3-D meso-scale model to obtain required data used as atmospheric parameters for the FASDOM code, such as the atmospheric profiles (pressure, temperature and water vapour profiles) and the state of the volcanic plume (altitude, thickness). Based on meteorological equations and on a simple tracer emission law, RAMS provides the spatial and temporal evolution of mass loading, its vertical distribution and its transport altitude (Minvielle et al., 2004a, b). Meteorological parameters of this model are initialized and nudged with ECMWF reanalysed $(0.5 \cdot 0.5 \mathrm{deg}$.) data (Uppala et al., 2005). The configuration of simulations consists of one grid $(10 \cdot 10 \mathrm{~km}$ as spatial resolution) for the studied area, with a vertical discretization of the atmosphere on 50 levels, including 20 levels below $10 \mathrm{~km}$. Note that this vertical discretization is identical to that used for the radiative transfer calculations. Simulations with RAMS are made during a period of several days to get the spin-up. The principal event simulated corresponds to the interesting case holding for different satellite observations on 6 May, when the volcano source emitted ash over several levels reaching $5 \mathrm{~km}$, as observed by Arason et al. (2011). Figure 3 presents the spatial distribution of the mass loading (vertically integrated) of ash plume. Similarly to the one observed in Fig. 1, the simulated plume resembles the shape of a comma due to the NE wind direction over Atlantic Ocean, not so far from the volcanic source. Simulations of spatial distribution are in agreement with observations, although the simulated plume shape appears broader than the observed one (see Sect. 5). Note
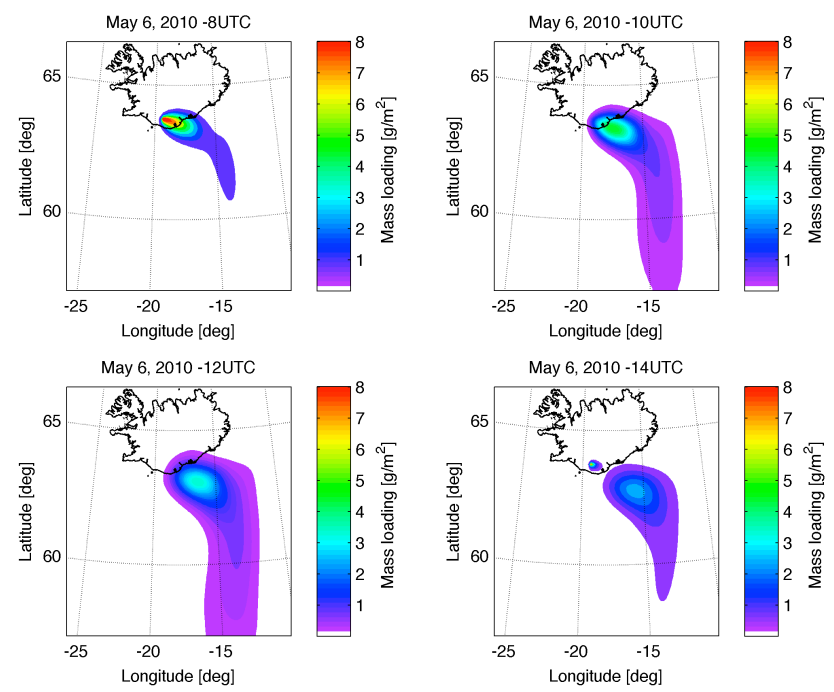

Fig. 3. Temporal and spatial evolution of mass loading obtained by the RAMS model on 6 May, from 08:00 to 14:00 UTC.

that the RAMS model is used here, only to provide atmospheric parameters for FASDOM. This spatial evolution and accurate forecasts of ash plume would be improved using an approach combining satellite observations and the regional transport model, as proposed by Boichu et al. (2013).

\section{Volcanic plume observation}

The algorithm presented in the previous section has been applied to the volcanic plume during the Eyjafjallajökull eruption on 6 May 2010 at 19:00 UTC, using BTD of SEVIRI channels at $11 \mu \mathrm{m}$ and $12 \mu \mathrm{m}$. This case study allows us to compare our retrievals with those obtained by Francis et al. (2012) in similar conditions. The optical thickness and mean effective radius retrievals are obtained assuming a lognormal formulation for a monomodal size distribution, and mass loading is then estimated from Eq. (3). Optical and physical properties are derived assuming a plume altitude of $6 \mathrm{~km}$ following the radar observations at $5.5-6.5 \mathrm{~km}$ (Icelandic Meteorological Office, IMO), even though it reached above $9 \mathrm{~km}$, according to Hjaltadóttir et al. (2010).

The retrievals of the optical thickness $\tau_{\mathrm{a}}$ at $12 \mu \mathrm{m}$, of the particle effective radius $r_{\mathrm{e}}(\mu \mathrm{m})$, and estimates of the mass loading $M\left(\mathrm{~g} \mathrm{~m}^{-2}\right)$ are presented in Fig. 4. As mentioned in Sect. 3.2, the retrieval algorithm is applied to a given pixel for each particle type reported in Table 1 and several solutions are then possible for $r_{\mathrm{e}}$ and $M$. Results presented in Fig. 4 are the mean values of these parameters and they are close to those obtained by Francis et al. (2012) for the same scene, but using only Andesite refractive index data (Pollack et al., 1973). In our study, mass loading and effective radius of particles are generally of the order of $1-4 \mathrm{~g} \mathrm{~m}^{-2}$ and $2-5 \mu \mathrm{m}$, respectively; higher values are observed near the source and 
can reach $10 \mathrm{~g} \mathrm{~m}^{-2}$ and $8 \mu \mathrm{m}$, respectively. The mean effective particle radius in Fig. 4 is $r_{\mathrm{e}}=4.5 \mu \mathrm{m} \pm 0.8 \mu \mathrm{m}$. The $r_{\mathrm{e}}$ uncertainty is defined as the average of mean deviations obtained for each pixel due to multiple solutions. This uncertainty shows a large dispersion in retrieved effective radius by applying the algorithm with several particle types and confirms that retrievals are strongly dependent on the choice of ash refractive index data (Wen and Rose, 1994; Francis et al., 2012). The maximum mass loading $\left(10 \mathrm{~g} \mathrm{~m}^{-2}\right)$ is slightly higher than those retrieved by Francis et al. (2012) of about $8 \mathrm{~g} \mathrm{~m}^{-2}$. The methodology and particle types used in this study can explain this difference. Indeed, the retrieval algorithm employed by Francis et al. (2012) is based on a onedimensional variational analysis, using SEVIRI data and Andesite refractive indices, with retrievals of the layer altitude, the mass loading and the size distribution effective radius, assuming that all other parameters of the ash plume are known. The altitude of the plume is then simultaneously retrieved with other physical parameters and not fixed as in our algorithm. The altitude retrieved by Francis et al. (2012) ranges from 3 to $12 \mathrm{~km}$, with most pixels between 5 and $10 \mathrm{~km}$. These results allow us to have confidence in plume parameters retrieved from our algorithm.

Additional simulations (not presented here) were then performed to test the potential of the channel at $8.7 \mu \mathrm{m}$ to better constrain retrievals. Note that the spectral range around $8.7 \mu \mathrm{m}$ can be affected by the $\nu_{1}$ absorption band of $\mathrm{SO}_{2}$, which may appear in high concentration during volcanic eruptions. However, low levels of $\mathrm{SO}_{2}$ were generally observed during the Eyjafjallajökull eruptions. These simulations have shown that retrievals are also possible using the channel at $8.7 \mu \mathrm{m}$. Nevertheless, the use of a third channel $(8.7 \mu \mathrm{m})$ does not allow us to constrain enough the particle type among the solutions retrieved with our algorithm. It is mainly due to the spectral characteristics of usual wide field-of-view sensors, with too large spectral bands to discriminate the particle type. In addition, analysis has revealed the complex composition of the volcanic plume. Indeed, in situ measurements for the Eyjafjallajökull eruption have shown that ash is composed with aggregates of various typologies (Bonadonna et al., 2011). Samples of volcanic ash collected near the source have shown a silica concentration of $58 \%$ (Sigmarsson et al., 2010), suggesting very fine andesite ash (Zehner et al., 2010). This composition can also vary as a function of time and eruptions, and hyperspectral sounders are necessary to distinguish aerosol type (Clarisse et al., 2010a).

\section{Comparisons of satellite retrievals using different infrared instruments}

The algorithm presented in Sect. 3 was applied in the same way to brightness temperatures measured by MODIS/Terra (at 11:55 UTC), SEVIRI (at 12:00 UTC) and
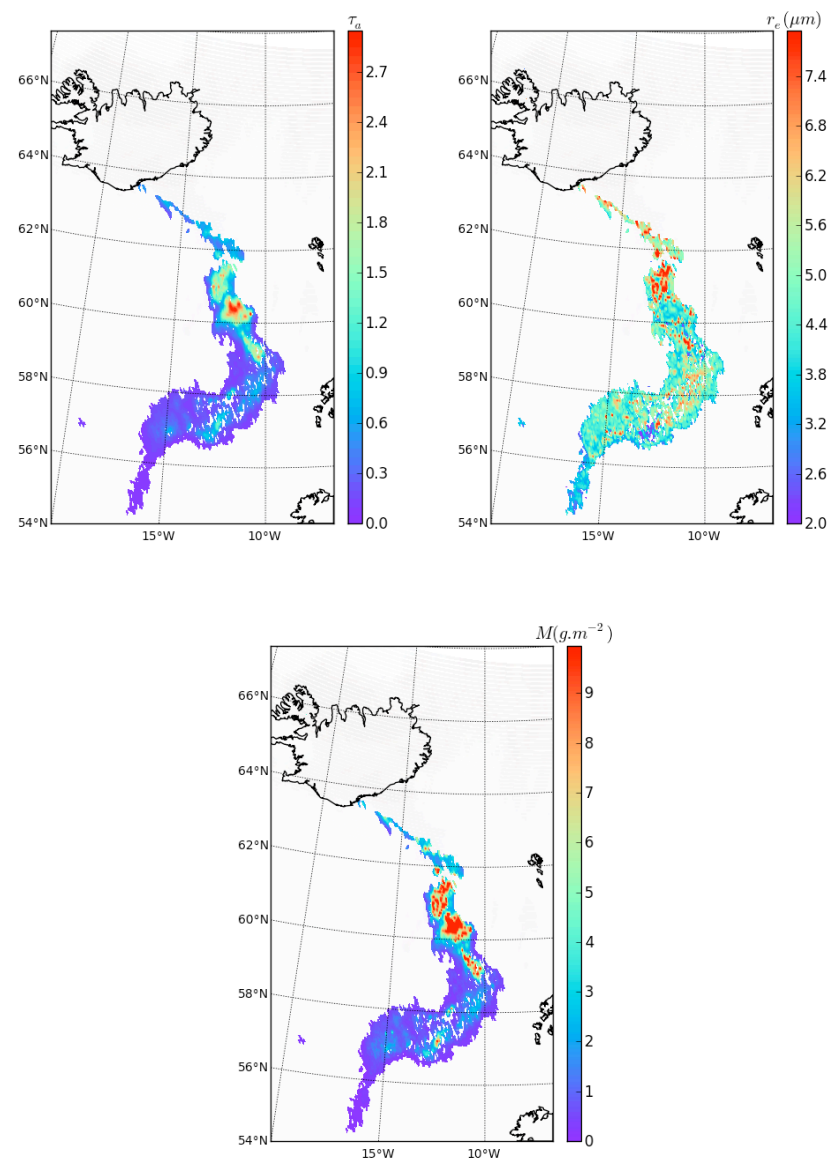

Fig. 4. Optical thickness at $12 \mu \mathrm{m} \tau_{\mathrm{a}}$, effective radius $r_{\mathrm{e}}$ and mass loading $M$ retrieved using SEVIRI data on 6 May 2010 at 19:00 UTC. Retrievals are defined as mean values obtained from several particle models (see Sect. 4 for details), assuming a lognormal formulation for the size distribution and using BTD from SEVIRI channels at $10.8 \mu \mathrm{m}$ and $12 \mu \mathrm{m}$.

IASI (mid-morning data), following the approach outlined in Sect. 4, but for the plume on 6 May presented in Fig. 1. Indeed, due to orbital characteristics of the satellites, this case study allows us to compare near-simultaneous retrievals from MODIS/TERRA and SEVIRI. For the IASI sensor, physical parameters were retrieved from orbits corresponding to the morning. This inter-comparison allows us to analyse retrievals from instruments with different spatial resolutions and with slightly different spectral configurations but obtained with the same retrieval algorithm.

Figure 5 presents retrievals for the plume using channels at $11 \mu \mathrm{m}$ and $12 \mu \mathrm{m}$. The spatial distributions are similar for retrieved parameters from the three instruments and also appear close to those obtained from the RAMS model (Fig. 3). In addition, Table 2 presents the mean retrieved values from SEVIRI, IASI and MODIS, for the optical thickness $\tau_{\mathrm{a}}$ at $12 \mu \mathrm{m}$, the effective radius $r_{\mathrm{e}}$ and the mass loading $M$. The latter allows a more quantitative analysis and shows a close 

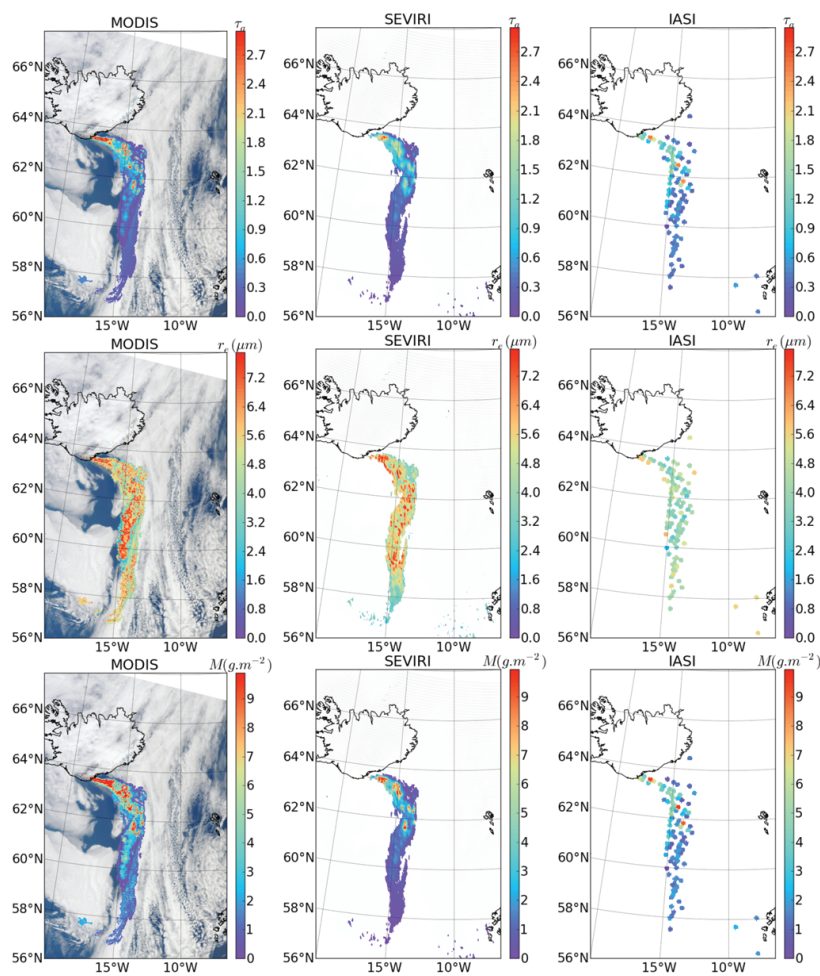

Fig. 5. Retrievals of optical thickness $\tau_{\mathrm{a}}$ at $12 \mu \mathrm{m}$ (top), effective radius $r_{\mathrm{e}}$ (middle) and mass loading $M$ (bottom) on 6 May, using MODIS/Terra (11:55 UTC), SEVIRI (12:00 UTC) and IASI (midmorning data).

agreement between the effective radius retrievals. However, retrievals for the optical thickness and estimates of the mass loading are higher for MODIS and IASI. Deviations with SEVIRI retrievals may be explained by differences in spectral characteristics and the viewing angle of instruments (see Sect. 2). In addition, the spectral response of SEVIRI channels is slightly different from the one of MODIS, in particular for the channel centred at $10.8 \mu \mathrm{m}\left(926 \mathrm{~cm}^{-1}\right)$ with a spectral width of about $2 \mu \mathrm{m}\left(200 \mathrm{~cm}^{-1}\right)$ and that can be compared with those of MODIS (see Fig. 2).

Consequently, it seems difficult to evaluate the consistency of retrievals due to differences in spatial and spectral characteristics of instruments, and no quantitative conclusion can be drawn at this stage. In order to get a quantitative analysis of satellite retrievals, a detailed inter-comparison study was conducted in two stages: firstly, sensitivity of our retrieval algorithm to the model parameter uncertainties was evaluated; secondly, the influence of the spatial and spectral characteristics of the sensors on retrieved parameters was analysed and compared with the retrieval errors estimated in the previous sensitivity analysis.
Table 2. Mean values retrieved for the ash optical thickness $\tau_{\mathrm{a}}$ and the effective radius $r_{\mathrm{e}}$, and estimated for the mass loading $M$ and the total mass loading $M_{\mathrm{T}}$, for the plume on 6 May 2010, as a function of the satellite configuration. Note that SEVIRI retrievals correspond to larger viewing angles, contrary to the other satellite configurations.

\begin{tabular}{lrrrr}
\hline Satellite configuration & $\tau_{\mathrm{a}}$ & $r_{\mathrm{e}}(\mu \mathrm{m})$ & $M\left(\mathrm{~g} \mathrm{~m}^{-2}\right)$ & $M_{\mathrm{T}}(\mathrm{kt})$ \\
\hline SEVIRI & 0.42 & 4.2 & 1.9 & 162 \\
IASI & 0.54 & 4.4 & 2.3 & 200 \\
MODIS & 0.53 & 4.7 & 2.6 & 221 \\
MODIS_as_IASI & 0.52 & 4.4 & 2.5 & 213 \\
IASI_as_SEVIRI & 0.56 & 4.5 & 2.4 & 204 \\
IASI_as_MODIS & 0.55 & 4.9 & 2.7 & 230 \\
\hline
\end{tabular}

\subsection{Estimation of the uncertainties in retrieved parameters}

Sensitivity of our retrieval algorithm to main atmospheric parameters was estimated using the plume on 6 May at 12:00 UTC presented in Fig. 1 and Fig. 5, to quantify the retrieved parameters' uncertainties. Retrievals were calculated for the different instruments assuming errors in the following input parameters:

- Temperature surface and profile: a realistic error $(\Delta T=1 \mathrm{~K})$ has been considered on each layer of the temperature profile as well as on surface temperature, compatible with the typical values used for the ECMWF assimilation.

- Water vapour profile: an error of $\Delta \mathrm{H}_{2} \mathrm{O}=10 \%$ at each atmospheric level was considered. The latter is compatible with typical a posteriori uncertainties from operational Level 2 of dedicated instruments such as IASI (Clerbaux et al., 2007).

- Layer thickness and altitude: an error of $\Delta z=1 \mathrm{~km}$ was supposed on the thickness or the altitude of the volcanic plume, assuming a constant optical thickness. This error can be considered as a maximal value for the plume thickness and seems reasonable for the altitude in comparison with the observed altitudes for the plume, generally between 2 and $8 \mathrm{~km}$.

- Aerosol type: the uncertainty due to the particle type used for retrievals was evaluated by calculating the mean difference between plume parameters derived from the Andesite refractive index and from the other types of particles presented in Table 1. Andesite has been selected as a reference case because several authors have noticed that Andesite refractive index data can be considered as a suitable approximation for volcanic ash (e.g. Wen and Rose, 1994; Prata and Grant, 2001; Francis et al., 2012). 
Table 3. Uncertainties (in \%) in the ash optical thickness $\tau_{\mathrm{a}}$, the effective radius $r_{\mathrm{e}}$ and the mass loading $M$, retrieved with the algorithm presented in Sect. 3 for the plume on 6 May, as a function of the instrument and as a function of the errors $(\Delta)$ in the input atmospheric parameters.

\begin{tabular}{|c|c|c|c|c|c|c|c|c|c|c|}
\hline \multirow{2}{*}{$\begin{array}{l}\text { Uncertainties } \\
(\%)\end{array}$} & \multirow[b]{2}{*}{ Errors $\Delta$} & \multicolumn{3}{|c|}{$\tau_{\mathrm{a}}$} & \multicolumn{3}{|c|}{$r_{\mathrm{e}}$} & \multicolumn{3}{|c|}{$M$} \\
\hline & & MODIS & SEVIRI & IASI & MODIS & SEVIRI & IASI & MODIS & SEVIRI & IASI \\
\hline Surface temperature & $1 \mathrm{~K}$ & 8 & 4 & 7 & 8 & 2 & 6 & 12 & 4 & 8 \\
\hline Temperature profile & $1 \mathrm{~K}$ & 4 & 8 & 3 & 8 & 5 & 3 & 8 & 10 & 3 \\
\hline Water vapour profile & $10 \%$ & 2 & 4 & $<1$ & 4 & 5 & $<1$ & 4 & 6 & $<1$ \\
\hline Layer thickness & $1 \mathrm{~km}$ & 10 & 8 & 10 & 7 & 6 & 6 & 12 & 8 & 8 \\
\hline Aerosol type & See Sect. 5.1. & 4 & 5 & 6 & 15 & 12 & 20 & 14 & 10 & 15 \\
\hline Layer altitude & $1 \mathrm{~km}$ & 20 & 16 & 18 & 10 & 14 & 10 & 18 & 14 & 15 \\
\hline $\begin{array}{l}\text { Size distribution } \\
(\text { standard deviation } \sigma \text { ) }\end{array}$ & 0.5 & 6 & 7 & 6 & 18 & 20 & 25 & 48 & 52 & 55 \\
\hline
\end{tabular}

- Size distribution: a deviation on the geometric standard deviation $\sigma$ of the particle size distribution was considered in the range 1.5-2.5 (Francis et al., 2012). The standard deviation $\sigma=2$, considered as the reference in calculations, is used by default in this study.

Uncertainties (in \%) in $\tau_{\mathrm{a}}, r_{\mathrm{e}}$ and $M$, resulting from errors in atmospheric model parameters of the retrieval algorithm, are presented in Table 3. These uncertainties were estimated through retrievals performed with the algorithm presented in Sect. 3, for the three instruments, as a function of errors in atmospheric parameters as defined above. Specifically, uncertainties were calculated as the mean difference, for the entire plume, between retrieved plume parameters using input atmospheric parameters from the RAMS model and the ones retrieved considering errors in these input parameters. Table 3 shows that the uncertainties due to surface and profile temperature, water vapour profile and layer thickness generally remains under $10 \%$ for retrieved parameters and are close for the three instruments. Note that the uncertainty due to water vapour is weak for IASI channels, which have been selected without gaseous line absorption. On the other hand, uncertainties in retrievals are very important in the case of errors due to ash particle type, ash layer altitude and particle size distribution, which is consistent with the fact that infrared measurements are mainly sensitive to these parameters (Herbin et al., 2013). Especially, uncertainties are always above $10 \%$ in the case of errors in the layer altitude or particle types, and can reach $50 \%$ in the case of errors in the size distribution for effective radius and mass loading estimates. These last parameters appear to be the most important a posteriori error sources. Table 3 also shows that retrievals are sensitive to the refractive indices (Francis et al., 2012) and, above all, to the particle size distribution. These conclusions agree with Wen and Rose (1994), who reported that the mass loading is more sensitive to the particle size distribution (considering a uniform, a lognormal and a gamma size distribution) than it is to the plume composition. Finally, Table 3 shows that uncertainties are globally equivalent for the three instruments, and errors in atmospheric parameters do not explain deviations observed on retrievals between the three instruments. Consistency between retrievals was analysed in Sect. 5.2 using the same viewing configuration for IASI and MODIS.

\subsection{Inter-comparison of retrieved parameters}

To evaluate the consistency of the observations, comparisons of retrieved and estimated parameters were performed using MODIS, SEVIRI and IASI data in the same spatial or spectral configuration, for the plume on 6 May at 12:00 UTC. The following satellite configurations were defined as follows:

- MODIS_as_IASI: retrieved parameters obtained from MODIS brightness temperatures were averaged over the same IFOV as IASI.

- IASI_as_MODIS: retrievals are obtained using an IASI high-spectral resolution spectrum integrated over the MODIS spectral response and treated in the algorithm as MODIS data.

- IASI_as_SEVIRI: retrievals are also obtained using an IASI high-spectral resolution spectrum integrated over the SEVIRI spectral response and treated in the algorithm as SEVIRI data.

Table 2 summarizes the mean values obtained for the ash optical thickness, $\tau_{\mathrm{a}}$, and the effective radius, $r_{\mathrm{e}}$, as well as estimations of the mass loading, $M$, for the previous three configurations.

- Influence of the spatial resolution on the retrievals: a comparison of results obtained for the MODIS and MODIS_as_IASI configurations in Table 2 allows us to verify the consistency of retrievals. Indeed, in this case the retrievals differences are on the order of $5 \%$ and are weaker than uncertainties due to atmospheric model parameter errors (see Sect. 5.1). Moreover, the mean effective radius and the mass loading obtained 


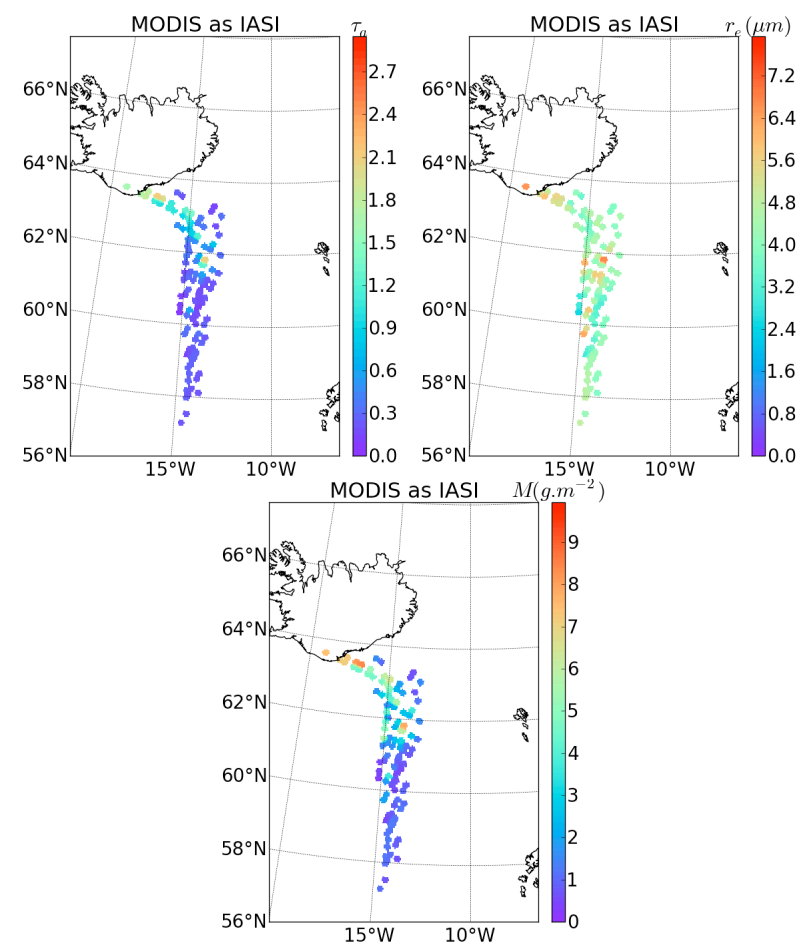

Fig. 6. Same as Fig. 5, but for MODIS_as_IASI configurations (i.e. retrieved parameters obtained from MODIS brightness temperatures averaged over the same IFOV as IASI).

by averaging MODIS retrievals over the same IFOV as IASI (MODIS_as_IASI configuration) are closer to those obtained with IASI (Table 2). This conclusion is also illustrated in Fig. 6 that presents the spatial distribution of the retrieved optical thickness and effective radius, as well as the mass loading $M$ estimation in the MODIS_as_IASI configuration. Figure 6 has to be compared with retrievals of IASI presented in Fig. 5 and shows a satisfactory level of agreement. Finally, residual deviations between retrievals can also be explained by the sampling or viewing differences and, to a lesser extent, time differences. Indeed, IASI measurements correspond to the orbits of the morning while MODIS products correspond to BT measured at 11:55 UTC.

- Influence of the spectral resolution on the retrievals: the influence of the spectral response of sensors was estimated using IASI spectra as a reference. Parameters were retrieved from brightness temperatures obtained by integrating IASI spectra over the SEVIRI or MODIS spectral response (IASI_as_SEVIRI and IASI_as_MODIS configurations). In this case, retrievals are obtained in the same viewing geometry and spatial resolution. Table 2 presents deviations on the order of 10 to $15 \%$ between retrievals obtained for IASI_as_SEVIRI and IASI_as_MODIS,
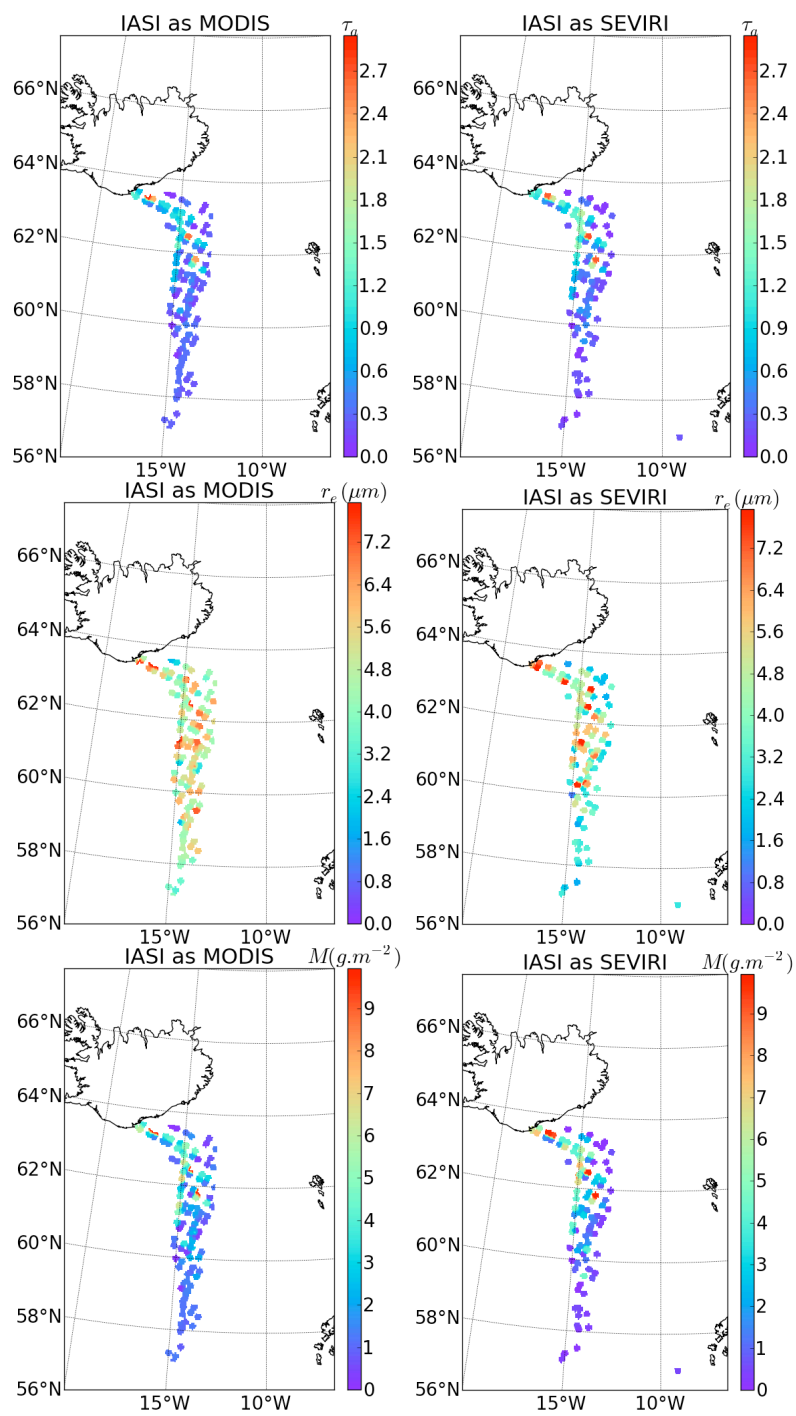

Fig. 7. Same as Fig. 5, but for IASI_as_MODIS (left) and IASI_as_SEVIRI (right) configurations, i.e. retrievals are obtained using IASI spectra convoluted with the MODIS (or SEVIRI) spectral response and treated in the algorithm as MODIS (or SEVIRI) data.

for the effective radius and the mass loading respectively. These deviations are non-negligible but remain on the order of those due to atmospheric parameters (Table 3). These differences are due to the different spectral response functions of SEVIRI and MODIS, as noticed previously (width and spectral position of the SEVIRI channel at $10.8 \mu \mathrm{m}$ ). In addition, these deviations are weaker than those between SEVIRI and MODIS and confirm the consistency of retrievals when compared in similar conditions. These results allow us to conclude that the larger deviations obtained in Table 2 are inherent to the different viewing geometry of the sensors. Note also that the retrievals obtained for IASI_as_MODIS are closer to 
the results from MODIS than those obtained for IASI. This spectral consistency is also illustrated in Fig. 7 that presents close spatial distributions of retrieved parameters in two configurations, despite their different spectral characteristics.

Furthermore, an estimation of the total mass loading $M_{\mathrm{T}}$ of the plume considered in this section (e.g. 6 May, 12:00 UTC) was done using previous satellite retrievals. The area covered by the volcanic plume was first calculated using geo-coordinates of retrievals in Fig. 6 and estimated at $85000 \mathrm{~km}^{2}$. The total ash mass loading was then calculated as the product of the estimated plume area and the mean retrieved mass loading $M$. Estimations of the total mass loading $M_{\mathrm{T}}$ are presented in Table 2 for each satellite configuration and $M_{\mathrm{T}}$ can be estimated at $205 \mathrm{kt} \pm 22 \mathrm{kt}$. This total mass loading can be compared with that calculated by Labazuy et al. (2012) for the same plume situation, from an equivalent methodology based on inversions of the SEVIRI infrared data. Labazuy et al. (2012) calculated a total ash mass of $210 \mathrm{kt}$ for 6 May and this estimate is consistent with the range of retrieved $M_{\mathrm{T}}$ from our retrievals.

\section{Conclusions}

An inter-comparison of ash plume parameters obtained with the same retrieval algorithm from measurements of infrared instruments, commonly used for the monitoring of volcanic ash (MODIS, SEVIRI and IASI), has been presented. Retrievals obtained from these instruments, as well as those obtained from IASI and MODIS in similar spatial and spectral configurations, have been compared. The results of this intercomparison, as a whole, allow us to conclude that retrievals are in close agreement, despite the different spectral and spatial characteristics of the sensors and compared to uncertainties due to errors in input atmospheric parameters. Our study has also confirmed that uncertainties in retrievals are mainly due to errors in the plume height, the particle composition and, most of all, the particle size distribution. This analysis demonstrates the consistency of observations and the robustness of the method to retrieve the optical thickness and the effective particle size, and to estimate the mass concentration of volcanic particles. However, the limitations of broadband sensors, to distinguish aerosol type with a limited number of spectral bands, have been confirmed.

In this study, high-spectral resolution spectra of IASI have been convoluted with the MODIS or SEVIRI spectral response functions to compare the retrievals in the same conditions. Nevertheless, high-spectral resolution measurements can be very useful for the characterisation of the plume composition (Clarisse et al., 2010b). Indeed, in the case of multispectral information of the TANSO-FTS instrument, Herbin et al. (2013) have shown that this approach enables simultaneous retrievals of gas profiles and up to seven aerosol parameters, including the aerosol optical thickness, mean geometric radius and standard deviation for coarse and fine modes, mean altitude of the aerosol layer, and aerosol layer width. Theses studies highlight the capabilities of hyperspectral data to improve the remote sensing of volcanic ash plumes.

Acknowledgements. This work was supported by the "Centre National d'Etudes Spatiales" (CNES - TOSCA), and the "Programme National de Télédétection Spatiale" (PNTS/AO2010533409). The authors thank the ICARE Data and Services Center (www.icare.univ-lille1.fr, for SEVIRI, MODIS and IIR data), Ether CNES/CNRS-INSU (Ether website http://www.pole-ether.fr, for IASI data) for providing access to satellite data, and the CINES (Centre Informatique National de l'Enseignement Supérieur) French national computing centre for donation of computational time.

Edited by: O. Dubovik

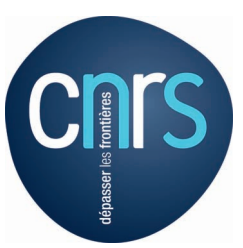

The publication of this article is financed by CNRS-INSU.

\section{References}

Alexander, D.: Volcanic Ash in the Atmosphere and Risks for Civil Aviation: A Study in European Crisis Management, Int. J. Disaster Risk Sci., 4, 9-19, doi:10.1007/s13753-013-0003-0, 2013.

Arason, P., Petersen, G. N., and Bjornsson, H.: Observations of the altitude of the volcanic plume during the eruption of Eyjafjallajökull, April-May 2010, Earth Syst. Sci. Data, 3, 9-17, doi:10.5194/essd-3-9-2011, 2011.

Boichu, M., Menut, L., Khvorostyanov, D., Clarisse, L., Clerbaux, C., Turquety, S., and Coheur, P.-F.: Inverting for volcanic $\mathrm{SO}_{2}$ flux at high temporal resolution using spaceborne plume imagery and chemistry-transport modelling: the 2010 Eyjafjallajökull eruption case study, Atmos. Chem. Phys., 13, 8569-8584, doi:10.5194/acp-13-8569-2013, 2013.

Bonadonna, C., Genco, R., Gouhier, M., Pistolesi, M., Cioni, R., Alfano, F., Hoskuldsson, A., and Ripepe, M.: Tephra sedimentation during the 2010 Eyjafjallajökull eruption (Iceland) from deposit, radar, and satellite observations, J. Geophys. Res., 116, B12202, doi:10.1029/2011JB008462, 2011.

Borde, R. and Dubuisson, P.: Sensitivity of Atmospheric Motion Vectors Height Assignment methods to semi-transparent cloud properties using simulated Meteosat- 8 radiances, J. Appl. Meteorol. Clim., 49, 1191-1204, 2010.

Clarisse, L., Prata, F., Lacour, J.-L., Hurtmans, D., Clerbaux, C., Coheur, P.-F.: A correlation method for volcanic ash detection using hyperspectral infrared measurements, Geophys. Res. Lett., 37, L19806, doi:10.1029/2010GL044828, 2010a.

Clarisse, L., Hurtmans, D., Prata, A. J., Karagulian, F., Clerbaux, C. De Mazière, M., and Coheur, P.-F.: Retrieving radius, concentration, optical depth, and mass of different types of aerosols from 
high-resolution infrared nadir spectra, Appl. Optics, 49, 37133722, 2010b.

Clerbaux, C., Hadji-Lazaro, J., Turquety, S., George, M., Coheur, P.-F., Hurtmanns, D., Wespes, C., Herbin, H., Blumstein, D., Tournier, B., and Phulpin, T.: The IASI/MetOp I mission: First observations and highlights of its potential contribution to GMES, Space Res. Today, 168, 19-24, 2007.

Clerbaux, C., Boynard, A., Clarisse, L., George, M., Hadji-Lazaro, J., Herbin, H., Hurtmans, D., Pommier, M., Razavi, A., Turquety, S., Wespes, C., and Coheur, P.-F.: Monitoring of atmospheric composition using the thermal infrared IASI/MetOp sounder, Atmos. Chem. Phys., 9, 6041-6054, doi:10.5194/acp-9-6041-2009, 2009.

Cooper, S. and Garrett, T.: Identification of small ice crystals using passive radiometric observations, J. Appl. Meteorol., 49, 23342347, doi:10.1175/2010JAMC2466.1, 2010.

Corradini, S., Merucci, L., Prata, F., Silvestri, M., Musacchio, M., Spinetti, C., Piscini, A., and Buongiorno, M. F.: $\mathrm{SO}_{2}$ and ash plume retrievals using MSG-SEVIRI measurements. Test case: 24 November 2006, Mt. Etna eruption, IEEE USEREST Workshop, Naples 11-14 November, 2008.

Corradini, S., Merucci, L., and Arnau, F.: Volcanic ash cloud properties: comparison between MODIS satellite retrievals and FALL3D transport model, IEEE Geosci. Remote S, 8, 248-252, 2011.

Cotton, W. R., Pielke, R. A., Walko, R. L., Liston, G. E., Tremback, C. J., Hiang, H., McAnelly, R. L., Harrington, J. Y., Nicholls, M. E., Carrio, G. G., and McFadden, J. P.: RAMS 2001: Current status and future directions, Meteorol. Atmos. Phys., 82, 5-29, 2003.

Doutriaux-Boucher, M. and Dubuisson, P.: Detection of volcanic $\mathrm{SO}_{2}$ by spaceborne infrared radiometers, Atmos. Res. doi:10.1016/j.atmosres.2008.08.009, 92, 69-79, 2009.

Dubovik, O., Holben, B., Eck, T. F., Smirnov, A., Kaufman, Y. J., King, M. D., Tanré, D., and Slutsker, I.: Variability of absorption and optical properties of key aerosol types observed in worldwide locations, J. Atmos. Sci., 59, 590-608, 2002.

Dubuisson, P., Giraud, V., Chomette, O., Chepfer, H., and Pelon, J.: Fast radiative transfer modeling for infrared imaging radiometry, J. Quant. Spectrosc. Ra., 95, 201-220, 2005.

Dubuisson P., Giraud, V., Pelon, J., Cadet, B., and Yang, P.: Sensitivity of thermal infrared radiation at the top of the atmosphere and the surface to ice cloud microphysics, J. Appl. Meteorol. Clim., 2545-2560, doi:10.1175/2008JAMC1805.1, 2008.

Francis, P. N., Cooke, M. C., and Saunders, R.: Retrieval of physical properties of volcanic ash using Meteosat: A case study from the 2010 Eyjafjallajökull eruption, J. Geophys. Res., 117, D00U09, doi:10.1029/2011JD016788, 2012.

Garnier, A., Pelon, J., Dubuisson, P., Faivre, M., Chomette, O., Pascal, N., and Kratz, D. P.: Retrieval of Cloud Properties Using CALIPSO Imaging Infrared Radiometer. Part I: Effective Emissivity and Optical Depth, J. Appl. Meteorol. Clim., 51, 14071425, doi:10.1175/JAMC-D-11-0220.1, 2012.

Herbin, H., Labonnote, L. C., and Dubuisson, P.: Multispectral information from TANSO-FTS instrument - Part 2: Application to aerosol effect on greenhouse gas retrievals, Atmos. Meas. Tech., 6, 3313-3323, doi:10.5194/amt-6-3313-2013, 2013.
Hess, M., Koepke, P., and Schult, I.: Optical Properties of Aerosols and Clouds: The Software Package OPAC, B. Am. Meteoreol. Soc., 79, 831-844, 1998.

Hillger, D. W. and Clark, J. D.: Principal component image analysis of MODIS for volcanic ash. Part I: Most Important Bands and Implications for Future GOES Imagers, J. Appl. Meteorol., 41, 985-1001, 2002.

Hjaltadóttir, S., Sigmundsson, F., Oddsson, B., Hreinsdóttir, S., Roberts, M. J., and Sveinbjörnsson, H.: Eruption in Eyjafjallajökull Status report: 18:00 GMT, 6 May 2010, Icelandic Meteorological Office and Institute of Earth Sciences, University of Iceland, 6 May, 2010

International Civil Aviation Organization (ICAO): Manual on volcanic ash, radioactive material and toxic chemical clouds, ICAO Doc. 9766-AN/954, Montreal, Quebec, Canada, 2001.

Inoue, T.: On the temperature and effective emissivity determination of semi-transparent cirrus clouds by bi-spectral measurements in the window region, J. Meteorol. Soc. Jpn., 63, 88-98, 1985.

Inoue, T.: A cloud type classification with NOAA 7 split-window measurements, J. Geophys. Res., 92, 3991-4000, 1987.

Kratz, D. P.: The correlated k-distribution technique as applied to the AVHRR channels, J. Quant. Spectrosc. Ra., 53, 501-517, 1995.

Kuze, A., Suto, H., Nakajima, M., and Hamazaki, T.: Thermal and near infrared sensor for carbon observation Fourier-transform spectrometer on the Greenhouse Gases Observing Satellite for greenhouse gases monitoring, Appl. Optics, 48, 6716-6733, 2009.

Labazuy, P., Gouhier, M., Harris, A., Guéhenneux, Y., Hervo, M., Bergès, J.-C., Cacault, P., and Rivet, S.: Near real-time monitoring of the April-May 2010 Eyjafjallajökull ash cloud: an example of a web-based, satellite data-driven, reporting system, Int J. Environ. Poll., 48, 262-272, doi:10.1504/IJEP.2012.049673, 2012.

Lacis, A. A. and Oinas, V.: A Description of the correlated kdistribution method, J. Geophys. Res., 96, 9027-9064, 1991.

Le Treut, H., Somerville, R., Cubasch, U., Ding, Y., Mauritzen, C., Mokssit, A., Peterson, T., and Prather, M.: Historical Overview of Climate Change, in: Climate Change 2007: The Physical Science Basis, Contribution of Working Group I to the Fourth Assessment Report of the Intergovernmental Panel on Climate Change, edited by: Solomon, S., Qin, D., Manning, M., Chen, Z., Marquis, M., Averyt, K. B., Tignor, M., and Miller, H. L., Cambridge University Press, Cambridge, United Kingdom and New York, NY, USA, 2007.

Longtin, D. R., Shettle, E. P., Hummel, J. R., and Pryce, J. D.: A Wind Dependent Desert Aerosol Model: Radiative Properties, AFGL-TR-88-0112, Air Force Geophysics Laboratory, Hanscom AFB, MA, 1988.

Mehta, P., Harries, J. E., and Turner, D. D.: Effect of size distribution and particle shape on simulations of downwelling infrared spectra during Saharan dust storms, Current problems in atmospheric radiation, Proceedings of the International Radiation Symposium (IRS), Foz do Iguacu, Brazil, 3-8 August 2008, AIP Conf. Proc. 1100, 177-180, doi:10.1063/1.3116943, 2009.

Millington, S. C., Saunders, R. W., Francis, P. N., and Webster, H. N.: Simulated volcanic ash imagery: a method to compare NAME ash concentration forecasts with SEVIRI imagery for 
the Eyjafjallajökull eruption in 2010, J. Geophys. Res., 117, D00U17, doi:10.1029/2011JD016770, 2012.

Minvielle, F., Cautenet, G., Lasserre, F., Forêt, G., Cautenet, S., Léon, J.-F., Andreae, M. O., Mayol-Bracero, O. L., Gabriel, R., Chazette, P., and Roca, R.: Modeling of the transport of aerosols during INDOEX 1999 and comparison with experimental data, Part 1: carbonaceous aerosol distribution, Atmos. Environ., 38, 1811-1822, 2004a.

Minvielle, F., Cautenet, G., Lasserre, F., Forêt, G., Cautenet, S., Léon, J.-F., Andreae, M. O., Mayol-Bracero, O. L., Gabriel, R., Chazette, P., and Roca, R.: Modeling the transport of aerosols during INDOEX 1999 and comparison with experimental data. Part 2: continental aerosol and their optical depth, Atmos. Environ., 38, 1823-1837, 2004b.

Parol, F., Buriez J. C., Brogniez G., and Fouquart, Y.: Information Content of AVHRR Channels 4 and 5 with Respect to the Effective Radius of Cirrus Cloud Particles, J. Appl. Meteorol., 30, 973-984, doi:10.1175/1520-0450-30.7.973, 1991.

Pavolonis, M. J., Feltz, F. W., Heidinger, A. K., and Gallina, G. M.: A Daytime Complement to the Reverse Absorption Technique for Improved Automated Detection of Volcanic Ash, J. Atmos. Ocean. Technol., 23, 1422-1444, doi:10.1175/JTECH1926.1, 2006.

Pielke, R. A., Cotton, W. R., Walko, R. L, Tremback, C. J., Lyons, W. A., Grasso, L. D., Nicholls, M. E., Moran, M. D., Wesley, D. A., Leel, T. J., and Copeland, J. H.: A comprehensive meteorological modeling system RAMS, Meteorol. Atmos. Phys., 49, 69-91, 1992.

Pollack, J. B., Toon, O. B., and Khare, B. N.: Optical properties of some terrestrial rocks and glasses, Icarus, 19, 372-389, 1973.

Prata, A. J.: Infrared radiative transfer calculations for volcanic ash clouds, Geophys. Res. Lett., 16, 1293-1296, doi:10.1029/GL016i011p01293, 1989a.

Prata, A. J.: Observation of volcanic ash clouds using AVHRR-2 radiances, Int. J. Remote Sens., 10, 751-761, doi:10.1080/01431168908903916, 1989 b.

Prata, A. J. and Grant, I. F.: Retrieval of microphysical and morphological properties of volcanic ash plumes from satellite data: Application to Mt. Ruapehu, New Zealand, Q. J. Roy. Meteorol. Soc., 127, 2153-2179, 2001.

Prata, A. J. and Kerkmann, J.: Simultaneous retrieval of volcanic ash and $\mathrm{SO}_{2}$ using MSG-SEVIRI measurements, Geophys. Res. Lett., 34, L05813, doi:10.1029/2006GL028691, 2007.

Prata, A. J. and Tupper, A. T.: Aviation hazards from volcanoes: the state of the science, Nat. Hazards, 51, 239-244, doi:10.1007/s11069-009-9415-y, 2009.

Prata, A. J., Bluth, G., Rose, W., Schneider, D., and Tupper, A.: Comments on "Failures in detecting volcanic ash from a satellite-based technique", Remote Sens. Environ., 78, 341-346, doi:10.1016/S0034-4257(01)00231-0, 2001.

Prata, F. J. and Prata, A. T.: Eyjafjallajokull volcanic ash concentrations determined using SEVIRI measurements, J. Geophys. Res., 117, D00U23, doi:10.1029/2011JD016800, 2012.

Remer, L. A., Kaufman, Y. J., Tanré, D., Mattoo, S., Chu, D. A., Martins, J. V., Li, R.-R., Ichoku, C., Levy, R. C., Kleidman, R. G., Eck, T. F., Vermote, E., and Holben, B. N.: The MODIS aerosol algorithm, products and validation, J. Atmos. Sci., 62, 947-973, 2005 .
Schlüssel, P., Hultberg, T. H., Phillips, P. L., August, T., and Calbet, X.: The operational IASI Level 2 processor, Adv. Space Res., 36, 982-988, 2005.

Schmetz, J., Pili, P., Tjemkes, S., Just, D., Kerkmann, J., Rota, S., and Ratier, A.: In Introduction to Meteosat Second Generation (MSG), B. Am. Meteorol. Soc., 83, 977-992, doi:10.1175/15200477(2002)083<0977:AITMSG>2.3.CO;2, 2002.

Schneider, D. J., Rose, W. I., and Kelley, L.: Tracking of 1992 eruption clouds from Crater Peak vent of Mount Spurr Volcano, Alaska, using AVHRR, in: The 1992 eruptions of Crater Peak vent, Mount Spurr Volcano, Alaska, US, edited by: Keith, T. E. C., Geological Survey Bulletin B 2139, 27-36, 1995.

Shettle, E. P. and Fenn, R. W.: Models for the aerosols of the lower atmosphere and the effects of humidity variations on their optical properties, AFGL-TR-79-0214, 1979.

Sigmarsson, O., Óskarsson, N., Pórðarson, P., Larsen, G., and Höskuldsson, A.: Preliminary interpretations of chemical analysis of tephra from Eyjafjallajökull volcano, Institute of Earth Sciences - Nordic Volcanological Institute, 2 pp., 2010.

Sourdeval, O., Brogniez, G., Pelon, J., Labonnote, C.-L., Dubuisson, P., Parol, F., Josset, D., Garnier, A., Faivre, M., and Minikin, A.: Validation of IIR/CALIPSO Level 1 Measurements by Comparison with Collocated Airborne Observations during CIRCLE2 and Biscay '08 Campaigns, J. Atmos. Ocean. Tech., 29, 653667, doi:10.1175/JTECH-D-11-00143.1, 2012.

Stamnes, K., Tsay, S., Wiscombe, W., and Jayaweera, K.: Numerically stable algorithm for discrete-ordinate-method radiative transfer in multiple scattering and emitting layered media, Appl. Optics, 27, 2502-2509, 1988.

Thomas, H. E. and Watson, I. M.: Observations of volcanic emissions from space: current and future perspectives, Natural Hazards, 54, 323-354, doi:10.1007/s11069-009-9471-3, 2010.

Tupper, A., Carn, S., Davey, J., Kamada, Y., Potts, R., and Prata, F.: An evaluation of volcanic cloud detection techniques during recent significant eruption in the western Ring of Fire, Remote Sens. Environ., 91, 27-46, 2004.

Uppala, S. M., Kallberg, P. W., Simmons, A. J., Andrae, U., Costa Bechtold, V. da, Fiorino, M., Gibson, J. K., Haseler, J., Hernandez, A., Kelly, G. A., Li, X., Onogi, K., Saarinen, S., Sokka, N., Allan, R. P., Andersson, E., Arpe, K., Balmaseda, M. A., Beljaars, A. C. M., Berg, L. van d., Bidlot, J., Bormann, N., Caires, S., Chevallier, F., Dethof, A., Dragosavac, M., Fisher, M., Fuentes, M., Hagemann, S., Holm, E., Hoskins, B. J., Isaksen, L., Janssen, P. A. E. M., Jenne, R., McNally, A. P., Mahfouf, J.-F., Morcrette, J.-J., Rayner, N. A., Saunders, R. W., Simon, P., Sterl, A., Trenberth, K. E., Untch, A., Vasiljevic, D., Viterbo, P., and Woollen, J.: The ERA-40 re-analysis, Q. J. Roy. Meteorol. Soc., 131, 2961-3012, 2005.

Watson, I. M., Realmuto, V. J., Rose, W. I., Prata, A. J., Bluth, G. J. S., Gu, Y., Bader, C. E., and Yu, T.: Thermal infrared remote sensing of volcanic emissions using the moderate resolution imaging spectroradiometer, J. Volcanol. Geoth. Res., 135, 75-89, 2004.

Webley, P. W., Steensen, T., Stuefer, M., Grell, G., Freitas, S., and Pavolonis, M.: Analyzing the Eyjafjallajökull 2010 eruption using satellite remote sensing, lidar and WRF-Chem dispersion and tracking model, J. Geophys. Res., 117, D00U26, doi:10.1029/2011JD016817, 2012. 
Wen, S. and Rose, W. I.: Retrieval of sizes and total masses of particles in volcanic clouds using AVHRR channels 4 and 5, J. Geophys. Res., 99, 5421-5431, 1994.

Yu, T., Rose, W. I., and Prata, A. J.: Atmospheric correction for satellite-based volcanic ash mapping and retrievals using split window IR data from GOES and AVHRR, J. Geophys. Res., 107, 4311, doi:10.1029/2001JD000706, 2002.
Zehner, C.: Monitoring Volcanic Ash from Space, Proceedings of the ESA-EUMETSAT workshop on the 14 April to 23 May 2010 eruption at the Eyjafjoll volcano, South Iceland, Frascati, Italy, 26-27 May 2010, ESA-Publication STM-280, doi:10.5270/atmch-10-01, 2010. 